\title{
Effects of personal particulate matter on peak expiratory flow rate of asthmatic children
}

\author{
Chin-Sheng Tang ${ }^{\mathrm{a}, *}$, Li-Te Chang ${ }^{\mathrm{b}}$, Hsien-Chi Lee ${ }^{\mathrm{a}}$, Chang-Chuan Chan ${ }^{\mathrm{c}}$ \\ a Department of Public Health, College of Medicine, Fu Jen Catholic University, Taipei, Taiwan, ROC \\ ${ }^{\mathrm{b}}$ Department of Environmental Engineering and Science, Feng Chia University, Taichung, Taiwan, ROC \\ ${ }^{\mathrm{c}}$ Institute of Occupational Medicine and Industrial Hygiene, College of Public Health, National Taiwan University, Taipei, Taiwan, ROC
}

Received 2 December 2006; received in revised form 31 March 2007; accepted 10 April 2007

Available online 22 May 2007

\begin{abstract}
Many researches have shown that the particulate matter (PM) of air pollution could affect the pulmonary functions, especially for susceptible groups such as asthmatic children, where PM might decrease the lung function to different extents. To assess the effects of PM on health, most studies use data from ambient air monitoring sites to represent personal exposure levels. However, the data gathered from these fixed sites might introduce certain statistical uncertainties. The objectives of this study are to evaluate the effects of various size ranges of PM on peak expiratory flow rate (PEFR) of asthmatic children, and to compare the model performance of using different PM measurements (personal exposures versus fixed-site monitoring) in evaluation. Thirty asthmatic children, aged 6 to 12 years, who live near the fixed monitoring site in Sin-Chung City, Taipei County, Taiwan, were recruited for the study. Personal exposures to $\mathrm{PM}_{1}, \mathrm{PM}_{2.5}$, and $\mathrm{PM}_{10}$ were measured continuously using a portable particle monitor (GRIMM Mode 1.108, Germany). In addition, an activity diary and questionnaires were used to investigate possible confounding factors in their home environments. The peak expiratory flow rate of each participant was monitored daily in the morning and in the evening for two weeks. Results showed several trends, although not necessarily statistically significant, between personal PM exposures and PEFR measurements in asthmatic children. In general, notable findings tend to implicate that not only fine particles $\left(\mathrm{PM}_{2.5}\right)$ but also coarse particles $\left(\mathrm{PM}_{2.5-10}\right)$ are likely to contribute to the exacerbation of asthmatic conditions. Stronger lagged effect and cumulative effect of PM on the decrements in morning PEFR were also found in the study. Finally, results of linear mixed-effect model analysis suggested that personal PM data was more suitable for the assessment of change in children's PEFR than ambient monitoring data.
\end{abstract}

(C) 2007 Elsevier B.V. All rights reserved.

Keywords: Particulate matter; Coarse particle; Peak expiratory flow rate; Personal exposures; Asthmatic children

* Corresponding author. Department of Public Health, College of Medicine, Fu Jen Catholic University, 510 Chung Cheng Road, Hsinchuang, Taipei County 24205, Taiwan, ROC. Tel.: +886 2 29053433; fax: +886229056385 .

E-mail address: tangcs@mail.fju.edu.tw (C.-S. Tang).

\section{Introduction}

Numerous epidemiological researches have shown that respiratory morbidity and mortality and declines in lung function are associated with current levels of particulate pollution in urban air (Dockery et al., 1993; Pope et al., 1995; Vedal et al., 1998; Schwartz and Neas, 2000; Penttinen et al., 2001; Brunekreef and Holgate, 
2002). In these studies, particulate matter (PM) has usually been measured as the mass of particles smaller than $10 \mu \mathrm{m}\left(\mathrm{PM}_{10}\right)$ or $2.5 \mu \mathrm{m}\left(\mathrm{PM}_{2.5}\right)$ in diameter, with a central monitoring site serving as a surrogate for personal exposures. The relationship between particulate pollution and lung function, principally peak expiratory flow rate (PEFR), is mostly consistent, despite differences in definitions of outcome measurements and statistical methods used to model the relationship between air pollution and health (Neas et al., 1995; Gielen et al., 1997; Trenga et al., 2006; Bourotte et al., 2007).

Asthma is a priority regarding child health care in Taiwan. While the mortality rate related to asthma in Taiwan has slowly decreased over the past two decades, the prevalence of asthma under children has increased from $1.3 \%$ in 1974 to $10.8 \%$ in 1994 (Hsieh and Shen, 1988; Kuo et al., 2003; Jan et al., 2004). A recent study further suggested a slight increase in asthma prevalence for elementary school children in Taiwan, compared to the results reported 10 years ago (Chang et al., 2006). Not only has asthma become an important issue in public health, but uncontrolled asthma, which could result in higher demands on emergency services and hospitalization, is also a significant financial burden on health care systems (Barnes et al., 1996).

Despite the progress that has been made to date, comparatively few studies have directly assessed the relative contributions of different particle sizes to the deterioration of lung functions in asthmatic children. This is due, in part, to the difficulty of conducting short-term monitoring for personal exposures (Howard-Reed et al., 2000). To address this issue, we investigated the effects of particulate air pollution on peak expiratory flow rate in a group of children with asthma. The relationships between particles of different sizes ( 1 to $10 \mu \mathrm{m}$ ) and PEFR were examined. In addition, results of model performance using personal monitoring for particulate exposures were compared to those using data from a central ambient monitoring site.

\section{Methods}

\subsection{Study design}

This panel study was conducted to monitor changes in personal PM exposures and PEFR simultaneously for the subjects during December 2003 to February 2005. Thirty asthmatic children in Taipei County were recruited, all of whom were enrolled in the same elementary school and live within $2 \mathrm{~km}$ from a stationary monitoring site (Taiwan Particle Supersite), which is operated by Taiwan Environmental Protection Administration (Taiwan EPA). In each 2-week session, each subject completed both the continuous PM exposure assessment in the first five days and the PEFR monitoring procedure throughout the 14 session days. Asthma was diagnosed by a physician and was thus defined according to the criteria of the American Thoracic Society. At the beginning of each sampling session, field staff obtained data from each subject, including sex, age, height, weight, symptoms in the past 12 months, and medical history. Furthermore, household information such as presence of cockroaches, dust mites, mold, furry pets, carpeting, plants inside the house, home dampness, environmental tobacco smoke (ETS), gas cooking appliances, mosquito repellant, and incense burning were collected through walk-through survey by a technician. Field staff also collected information regarding environmental factors of physical nature such as whether the house contained an air cleaner or air conditioner, as well as the presence of outdoor traffic, industries, and temple pollution. The review board of the Environmental Protection Bureau of Taipei County approved the research protocol, and a written consent was obtained from each participant's parents before the study was launched.

\subsection{PEFR monitoring}

During the study, each subject performed PEFR maneuvers in the morning after awaking and in the evening near bedtime every day of the 2-week session. The subjects were instructed to take the measurements before taking any medication. The highest of three values from consecutive PEFR maneuvers in the morning, as well as in the evening, were retained for further analysis. Subjects were trained by field staff to handle the electronic PEFR monitor (Asthma Monitor PF-100, Microlife, Taiwan) properly and were given a standard operation procedure for self-measuring. PEFR measurements were recorded in the monitor automatically and were later downloaded by field staff.

\subsection{PM monitoring}

Personal exposures to different sizes of particles were measured continuously using a portable particle monitor (DUSTcheck Portable Dust Monitor, model 1.108, GRIMM Labortechnik Ltd., Germany). Mass concentrations of $\mathrm{PM}_{1}, \mathrm{PM}_{2.5}$, and $\mathrm{PM}_{10}$, as well as ambient temperature and relative humidity, were measured and recorded for one-minute periods. The raw data were then summarized to one-hour segments for statistical analysis. Mass concentrations of $\mathrm{PM}_{2.5-10}$ were obtained by subtracting the $\mathrm{PM}_{2.5}$ fraction from the concurrent $\mathrm{PM}_{10}$ levels. A similar approach was applied to derive the data 
for $\mathrm{PM}_{1-2.5}$ concentrations. Before and after field sampling seasons, the DUSTcheck monitor was calibrated by the manufacturer with reference methods.

To measure the participants' PM exposures during normal daytime activities, a field staff member carrying a DUSTcheck monitor was assigned to each subject from 07:00 to 21:00 daily. Detailed information on household activities and time-activity patterns of the monitored individual were noted in personal diaries. During each day, subjects reported various microenvironments they visited, including living room, bedroom, classroom, cram school, other non-residential indoor areas, and outdoor places. The information of diary entries was reconfirmed by the field staff member immediately after daily sampling. Personal PM exposures were only calculated if the DUSTcheck monitor was with the subject at least $75 \%$ of the time during sampling.

In addition to personal exposure monitoring, ambient $\mathrm{PM}_{2.5}$ and $\mathrm{PM}_{10}$ concentrations were measured at the Taiwan Particle Supersite using tapered-element oscillating microbalance (TEOM) monitors (model 1400a, Thermo Electron Corp., USA), an inertial instrument that measures particle mass in real time on an exchangeable filter cartridge by monitoring frequency changes of a tapered element. Results of collocating the DUSTcheck monitor with the TEOM (presented in our previous study) showed good association for PM levels measured by both monitors simultaneously, with $R^{2}$ values of 0.90 and 0.91 for $\mathrm{PM}_{10}$ and $\mathrm{PM}_{2.5}$, respectively (Chuang et al., 2005).

\subsection{Statistical analysis}

To estimate the time course of PM effects on PEFR, we calculated the PM exposure levels as the mean 24-h concentration for the day on which the effect on lung function was measured (lag 0 ), and for the 2 preceding days (lag 1 and lag 2). Also, cumulative particulate exposures were defined as the 2-day mean concentration of lag 0 and lag 1 (2-day mean), and the 3 -day mean concentration of lag 0 to lag 2 preceding that day (3-day mean).

Linear mixed-effect models were used to estimate the effect of particulate exposures on PEFR, adjusted for personal and meteorological variables. Such mixedeffect models have the advantage of adjustment for invariant variables by fixed-effect models and accounting for individual differences by random-effect models (Diggle et al., 2002; Chan and Wu, 2005; Bourotte et al., 2007). To control the potential confounding variables of subject characteristics and environmental factors, we treated each subject's gender, age, body mass index (BMI), history of respiratory or atopic disease in the
Table 1

Basic characteristics of 30 asthmatic children participating in the study

\begin{tabular}{ll}
\hline Characteristic & Statistics \\
\hline Gender $(n)$ (male/female) & $20 / 10$ \\
Age (years) & $10.0 \pm 2.1(7.0-13.0)$ \\
BMI $\left(\mathrm{kg} / \mathrm{m}^{2}\right)$ & $18.0 \pm 2.5(14.1-23.3)$
\end{tabular}

Acute exacerbation of asthma in past 12 months

$0[n(\%)] \quad 18(60 \%)$

$1[n(\%)] \quad 7(23 \%)$

$2[n(\%)] \quad 4(13 \%)$

$3[n(\%)] \quad 1(3 \%)$

Anti-inflammatory medication use

Yes $[n(\%)] \quad 11(37 \%)$

No $[n(\%)] \quad 19(63 \%)$

Respiratory or atopic disease in family

Yes $[n(\%)]$

No $[n(\%)]$

$25(83 \%)$

$5(17 \%)$

Presence of indoor air pollutants

ETS exposure $[n(\%)] \quad 9(30 \%)$

Mold $[n(\%)] \quad 13(43 \%)$

Cockroaches $[\mathrm{n}(\%)] \quad 19(63 \%)$

Incense burning $[n(\%)] \quad 13(43 \%)$

Presence of outdoor air pollutants

Industries $[n(\%)]$

Traffic exposure $[n(\%)]$

Temples $[n(\%)]$

Morning PEFR $(\mathrm{L} / \mathrm{min})(n=404)$

Evening PEFR (L/min) $(n=517)$

$1(3 \%)$

$3(10 \%)$

$6(20 \%)$

$235 \pm 94(77-635)$

$245 \pm 90(76-658)$

Values are mean \pm SD (range) unless otherwise noted.

family, ETS, acute asthmatic exacerbation in the past 12 months, ambient temperature and relative humidity, presence of indoor pollutants (yes/no), and presence of outdoor pollutants (yes/no) as fixed effects, and each subject as a random effect in the mixed-effect model. Particulate levels with different exposure metrics (lags 0-2, 2-day mean, and 3-day mean) were used to estimate the time course of particulate effects. To standardize the association between PM exposure and PEFR, the current study expresses results as the change in PEFR for an interquartile range (IQR) in PM levels, i.e. difference between the 25th and 75th percentiles (Lipfert and Wyzga, 1999). Furthermore, to compare the suitability of ambient PM levels with personal PM exposures for PEFR change assessment, the PM variable in linear mixed-effect models was included using either personal measurements or ambient concentrations measured at the central monitoring site. Statistical analyses were performed using the MIXED procedure in the S-Plus 2000 program (MathSoft Inc., Cambridge, MA, USA). Model selection was based on minimizing Akaike's 
Table 2

Summarized statistics for 1 -h personal exposures and ambient monitoring data during the study period

\begin{tabular}{lrrrrr}
\hline Variable & $N$ & Mean \pm SD & $I_{Q R}^{*}$ & Minimum & Maximum \\
\hline Personal exposures & & & & & \\
$\mathrm{PM}_{10}\left(\mu \mathrm{g} / \mathrm{m}^{3}\right)$ & 3639 & $51.8 \pm 39.5$ & 42.9 & 3.4 & 351.7 \\
$\mathrm{PM}_{2.5-10}\left(\mu \mathrm{g} / \mathrm{m}^{3}\right)$ & 3639 & $17.8 \pm 19.6$ & 15.9 & 0.3 & 195.7 \\
$\mathrm{PM}_{2.5}\left(\mu \mathrm{g} / \mathrm{m}^{3}\right)$ & 3639 & $34.0 \pm 28.9$ & 27.6 & 1.8 & 284.6 \\
$\mathrm{PM}_{1-2.5}\left(\mu \mathrm{g} / \mathrm{m}^{3}\right)$ & 3639 & $6.2 \pm 4.8$ & 4.6 & 0.3 & 86.8 \\
$\mathrm{PM}_{1}\left(\mu \mathrm{g} / \mathrm{m}^{3}\right)$ & 3639 & $27.8 \pm 25.3$ & 24.5 & 1.4 & 263.4 \\
Temperature $\left({ }^{\circ} \mathrm{C}\right)$ & 3577 & $27.1 \pm 5.2$ & 7.5 & 7.0 & 37.7 \\
Relative humidity $(\%)$ & 3639 & $60.9 \pm 10.1$ & 13.9 & 40.1 & 92.6 \\
& & & & & \\
Ambient monitoring data & & & & \\
$\mathrm{PM}_{10}$ & 3934 & $48.4 \pm 26.5$ & 32.0 & 0.6 & 176.5 \\
$\mathrm{PM}_{2.5-10}$ & 3934 & $17.0 \pm 10.6$ & 11.7 & 0.1 & 80.2 \\
$\mathrm{PM}_{2.5}$ & 3934 & $31.4 \pm 18.8$ & 21.3 & 0.1 & 128.4 \\
Temperature & 3934 & $23.2 \pm 6.4$ & 9.6 & 5.2 & 35.9 \\
Relative humidity & 3920 & $72.8 \pm 12.6$ & 15.3 & 22.3 & 99.7 \\
\hline
\end{tabular}

*IQR (interquartile range) $=\mathrm{Q} 3-\mathrm{Q} 1$.

information criterion (AIC) (Akaike, 1974; Delfino et al., 2004; Bourotte et al., 2007).

\section{Results}

The demographic data are summarized in Table 1. The study population consisted of 20 boys and 10 girls, with an average age of 10 years. Twelve of the subjects $(40 \%)$ had had at least one episode of acute asthma in the 12 months preceding the study, while only 11 children $(37 \%)$ were using anti-inflammatory medication. Among the participants, 9 children (30\%) were being exposed to ETS, and $13(43.3 \%)$ to residential incense burning. Finally, the average PEFR for the children was $240 \mathrm{~L} / \mathrm{min}$, ranging from 76 to $658 \mathrm{~L} / \mathrm{min}$ individually, with the mean and the range of PEFR slightly higher in the evening than in the morning.

Table 2 summarizes the PM monitoring data with different sizes, temperature and relative humidity. During the study period, $1-\mathrm{h}$ average personal exposures (mean $\pm \mathrm{SD}$ ) to $\mathrm{PM}_{10}, \mathrm{PM}_{2.5}$, and $\mathrm{PM}_{1}$ were $51.8 \pm 39.5$, $34.0 \pm 28.9$, and $27.8 \pm 25.3 \mu \mathrm{g} / \mathrm{m}^{3}$, respectively. The microenvironmental meteorological conditions were usually warm, with an hourly temperature of $27.1 \pm 5.2{ }^{\circ} \mathrm{C}$ and a relative humidity of $60.9 \pm 10.1 \%$. Additionally, irrespective of particle size, average ambient PM concentrations were lower than the corresponding personal PM exposures and showed less variability. Neither personal exposures nor ambient concentrations of $\mathrm{PM}_{2.5}$ exceeded the U.S. National Ambient Air Quality Standards (24-h standard of $35 \mu \mathrm{g} / \mathrm{m}^{3}$ for $\mathrm{PM}_{2.5}$ ) (US EPA, 2006).

To compare the lagged and cumulative effects of PM exposures on morning and evening PEFR measurements, results of the changes in PEFR for an interquartile range (IQR) increase in the PM exposures are presented in Table 3. Regarding lag modes (lags 0-2), only a slight variation in the evening PEFR was observed for different PM exposure metrics. For instance, regardless of the particle size, the evening PEFR changes with an increase in personal PM exposures measured on the same day (lag 0) were less than $5 \mathrm{~L} / \mathrm{min}$. On the other hand, though not statistically significant, a negative influence on morning PEFR changes was reported for different exposures (Fig. 1A). In addition, stronger lagged effects on morning PEFR were found for $\mathrm{PM}_{2.5-10}$ exposures as compared to those for the smaller-size particles $\left(\mathrm{PM}_{1-2.5}\right.$ and $\left.\mathrm{PM}_{1}\right)$.

Table 3

Changes in PEFR $(95 \% \mathrm{CI})$ for interquartile increase in personal PM exposures estimated by linear mixed-effects models*

\begin{tabular}{llllll}
\hline Mode & $\mathrm{N} \mathrm{PM}$ & $\mathrm{PM}_{2.5-10}$ & $\mathrm{PM}_{2.5}$ & $\mathrm{PM}_{1-2.5}$ & $\mathrm{PM}_{1}$ \\
\hline Morning PEFR & & & & \\
Lag 0 & $64-15.99(-45.07,13.08)$ & $-20.55(-45.83,4.73)$ & $-6.44(-30.18,17.29)$ & $-10.51(-39.93,18.91)$ & $-6.00(-29.85,17.85)$ \\
Lag 1 & $37-44.78(-117.64,28.08)$ & $-39.05(-104.16,26.06)$ & $-12.26(-77.6,53.09)$ & $-6.79(-72.97,59.4)$ & $-12.52(-77.93,52.9)$ \\
Lag 2 & $25-41.45(-98.32,15.41)$ & $-39.56(-79.56,0.44)$ & $-4.38(-54.79,46.03)$ & $-11.73(-107.13,83.66)$ & $-24.87(-71.49,21.74)$ \\
2-day mean & $36-59.91(-133.94,14.11)$ & $-37.15(-105.01,30.7)$ & $-44.06(-113.79,25.67)$ & $-32.16(-102.93,38.6)$ & $-45.67(-117.09,25.74)$ \\
3-day mean & $24-0.56(-101.7,100.57)$ & $-35.47(-127.32,56.38)$ & $-6.01(-101.48,89.46)$ & $-7.70(-100.26,84.87)$ & $-5.69(-105.96,94.59)$
\end{tabular}

Evening PEFR

\begin{tabular}{|c|c|c|c|c|c|}
\hline Lag 0 & $870.06(-21.55,21.68)$ & $-1.68(-19.13,15.78)$ & $1.17(-17.79,20.13)$ & $4.75(-15.13,24.64)$ & $0.50(-18.82,19.82)$ \\
\hline Lag 1 & $58-1.71(-23.91,20.49)$ & $1.59(-14.32,17.5)$ & $-4.98(-27.77,17.81)$ & $6.60(-16.05,29.25)$ & $16.66(-7.59,40.9)$ \\
\hline $\operatorname{g} 2$ & $2611.32(-17.17,39.81)$ & $0.86(-30.84,32.57)$ & $11.30(-11.55,34$ & $-6.38(-4$ & $11.60(-11.1,34.31)$ \\
\hline 2-day mean & $572.58(-29.32,34.49)$ & $5.97(-15.57,27.5)$ & $41.74(11.36,72.13)$ & $43.90(20.42,67.37)$ & $39.97(7.1,72.85)$ \\
\hline 3-day mean & $2630.91(-15.3,77.12)$ & $29.75(-1.69,61.18)$ & $28.21(-19.08,75.5)$ & $34.92(-9.71,79.56)$ & $-3.32(-66.14,59.5)$ \\
\hline
\end{tabular}

$\mathrm{CI}=$ confidence interval.

*Adjusted for gender, age, BMI, disease history of family, ETS exposure, acute asthmatic exacerbation in past 12 months, temperature, relative humidity, presence of indoor air pollutants, and presence of outdoor air pollutants. 

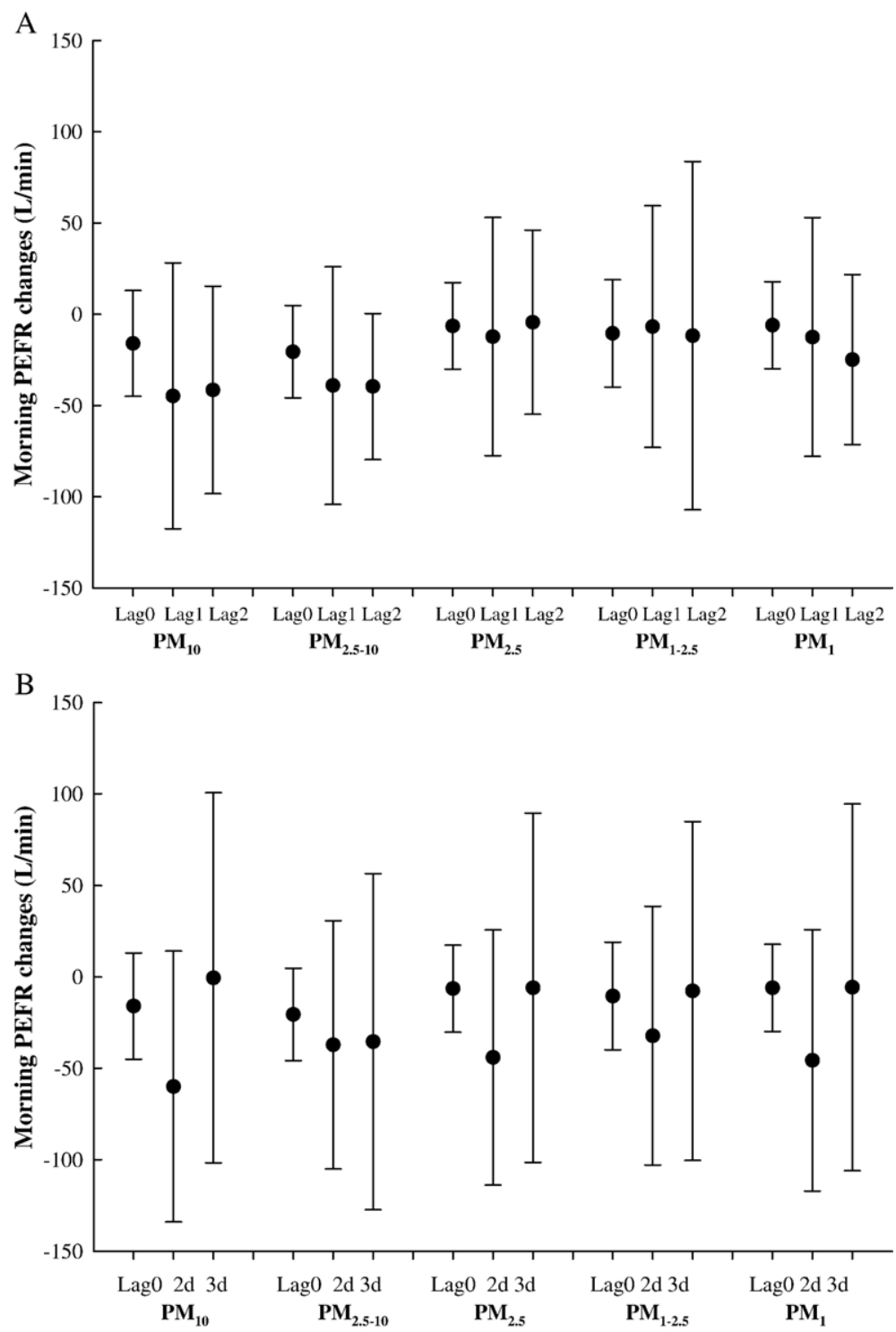

Fig. 1. Estimated lagged (A) and cumulative (B) effects of an interquartile increase in personal PM exposures on morning PEFR changes. Error bars indicate mean $\pm 95 \% \mathrm{CI}$.

The decrement in the morning PEFR for asthmatic children, for example, was $20.55 \mathrm{~L} / \mathrm{min}, 10.51 \mathrm{~L} / \mathrm{min}$, and $6.00 \mathrm{~L} / \mathrm{min}$ per increase of IQR for same day (lag 0) exposures to $\mathrm{PM}_{2.5-10}, \mathrm{PM}_{1-2.5}$, and $\mathrm{PM}_{1}$, respectively.

As to the cumulative modes (lag 0,2-day mean, 3-day mean), negative impacts (though statistically insignificant) on morning PEFR were also reported throughout exposures to different particle sizes (Table 3 ). In general, coarse particles $\left(\mathrm{PM}_{2.5-10}\right)$ had comparatively larger decreasing effects on morning PEFR than $\mathrm{PM}_{1-2.5}$ and $\mathrm{PM}_{1}$ (Fig. 1B). Among the three different cumulative modes, preceding 2-day mean of PM exposures indicated the strongest effects on decreasing morning PEFR in each of the PM size ranges. For example, the decrement in the morning PEFR was $39.56 \mathrm{~L} / \mathrm{min}, 11.73 \mathrm{~L} / \mathrm{min}$, and 24.87 L/min per increase of IQR for 2-day mean exposures to $\mathrm{PM}_{2.5-10}, \mathrm{PM}_{1-2.5}$, and $\mathrm{PM}_{1}$, respectively. Finally, for different cumulative modes, PM exposures of various size ranges showed little impact on reduction of evening PEFR.

To investigate the suitability of different types of PM data for PEFR change assessment, $\mathrm{PM}_{2.5}$ and $\mathrm{PM}_{10}$ levels measured at the central monitoring site (Taiwan Particle Supersite) were also applied in the linear mixed- 

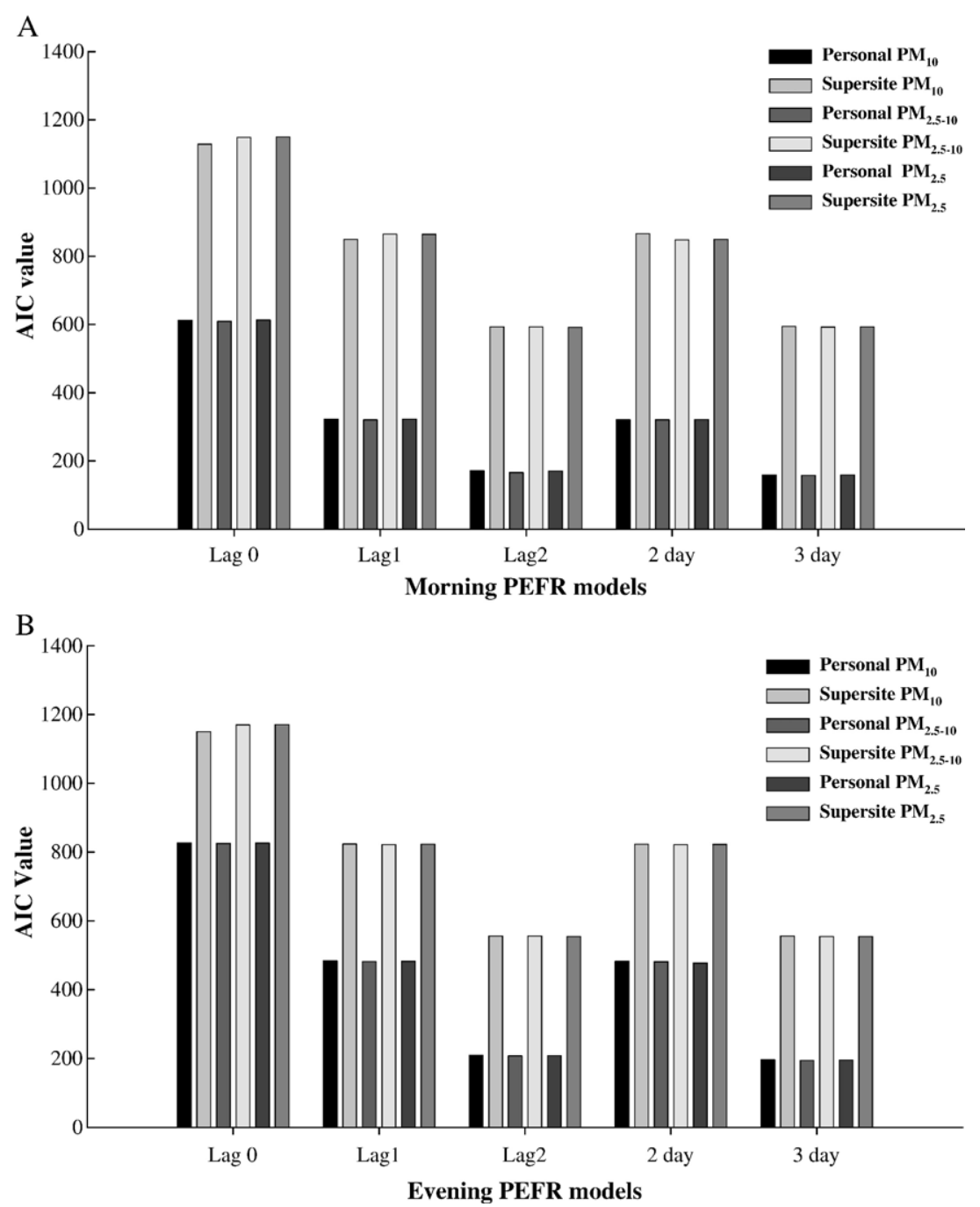

Fig. 2. Comparison of Akaike's information criterion (AIC) values for morning (A) and evening (B) PEFR changes estimated by linear mixed-effect models.

effect models to replace the corresponding personal PM measurements for comparison. As shown in Fig. 2, Akaike's information criterion values in the personal PM exposure models were consistently lower than those in the ambient PM models, indicating a better representativeness of personal monitoring on PEFR effect assessment. Moreover, for both of the lagged and cumulative effects, lag 2 and 3-day mean PM exposures, irrespective of particle size, had the lowest AIC values.

\section{Discussion}

In the current study, data of personal exposures to different sizes of PM were adopted in the analysis. On the other hand, most existing studies of PM and their association with lung function outcomes use total suspended particles (TSP), $\mathrm{PM}_{10}$, or $\mathrm{PM}_{2.5}$ from stationary ambient monitoring sites as the measurement for PM exposure, with rather limited data collected for $\mathrm{PM}_{1}$ measurements. Previous studies have suggested that exposure misclassification from using stationary PM data may have diminished the accuracy of exposureresponse estimates compared with personal exposures, thus potentially weakening associations with stationary PM (Delfino et al., 2004). To measure the participants' PM exposures during normal daytime activities and to avoid the change of activity patterns due to sampling inconvenience, in our study, personal PM exposures were measured by field staff carrying a DUSTcheck monitor with the subject throughout different microenvironments ( 7 am to $9 \mathrm{pm}$ ). At home during the night, the participants' parents were asked to take the monitor 
to different residential microenvironments with the children and make notes in the time-activity diary. The information of diary entries were reconfirmed by field staff the next morning to assure the data quality. Since the participants were all school children, their daily activities were actually less variable and were easier to follow properly as compared to those for adults. As shown in Fig. 2, the AIC values in the personal PM models were consistently lower than those in the corresponding ambient PM models. Recently, researchers found that personal PM was more strongly associated with forced expiratory volume in $1 \mathrm{~s}\left(\mathrm{FEV}_{1}\right)$ than was stationary-site PM, where the finding of stronger associations with personal PM exposures is also consistent with those in our study (Delfino et al., 2004).

Public health policies, in terms of establishing guidelines or standards for acceptable levels of ambient PM pollution, have been focusing primarily on indicators of fine particles $\left(\mathrm{PM}_{2.5}\right)$ and thoracic particles $\left(\mathrm{PM}_{10}\right)$ (WHO, 2005; US EPA, 2006). In the meantime, several studies suggest relative roles for $\mathrm{PM}_{10}$ and for both fine $\left(\mathrm{PM}_{2.5}\right)$ and coarse $\left(\mathrm{PM}_{2.5-10}\right) \mathrm{PM}$ mass fractions on pulmonary function changes, which is consistent with the findings in our study (Pekkanen et al., 1997; Peters et al., 1997a,b; Sheppard et al., 1999; Von Klot et al., 2002; Bourotte et al., 2007). Coarse PM is mainly deposited into the trachebronchial region of the respiratory tract, while the fine PM penetrates deeper into the alveolar region, where it may contribute to the release of particulate chemical constituents potentially bioavailable after inhalation and inducing an inflammatory reaction, which may lead to asthma exacerbation (Lighty et al., 2000; Espinosa et al., 2001). Even so, there is still limited evidence for a stronger effect of fine versus coarse fraction particles; also, submicron particles do not appear to have any notable stronger effect than other larger-diameter fine particles (Peters et al., 1997a,b; Yu et al., 2000; Penttinen et al., 2001; Von Klot et al., 2002; Brunekreef and Forsberg, 2005; Bourotte et al., 2007). Further studies are needed to identify the circumstances under which some classes of PM may cause little or no adverse reduction of lung function, as well as those under which PM components may cause notable effects.

The present study showed that the increase in PM was associated (though statistically insignificant) with decrements in PEFR, which was similar to those in previous epidemiological studies. In these studies, for both $\mathrm{PM}_{2.5}$ and $\mathrm{PM}_{10}$ pollution, the available point estimates for morning PEFR lagged 0 day (Pekkanen et al., 1997), lagged 1 day (Romieu et al., 1996, 1997; Gielen et al., 1997; Peters et al., 1997a,b), and lagged
2 days (Romieu et al., 1996; Timonen and Pekkanen, 1997; Segala et al., 1998) showed decreases, while the majority of the results were not statistically significant. On the other hand, in our study, stronger lagged effect (lag 2) and cumulative effect (2-day mean) of PM on PEFR were observed, which was not necessarily consistent with findings in earlier studies. Results from our study imply that effects of PM exposures on PEFR changes could be better predicted for longer exposure frames. A possible explanation is that the character of PM varied greatly from place to place and over time, depending upon factors such as pollution sources and the prevailing atmospheric conditions. Hence, a distributed lag model should more correctly capture all associations, because selection of any sole lag day would neglect associations on other lag days (Peters et al., 2001). Until now, to our knowledge, few data sets containing the everyday data required for a distributed lag analysis exist. Nevertheless, for those that have been analyzed for distributed lag, results showed more excess risk associated with a distributed lag analysis than with any single day analysis (Mar et al., 2003; Schwartz, 2003).

Furthermore, our results show a certain proportion of subjects $(30 \%)$ were exposed to ETS during the study period (Table 1). ETS has been identified as a significant contributor to measured 24-h personal $\mathrm{PM}_{2.5}$ exposures (Chang et al., 2003), and evidence has shown that exposure to ETS increases the risk of lower respiratory tract illness in children (Ferrence and Ashley, 2000). To control the effects of sidestream smoke in our study, ETS exposure was included in the mixed-effect model analysis and no significant impact on decreased PEFR was found, which could be attributed to the very small amount of time the subjects were exposed to ETS.

In our results, adverse effect trends of PM were observed on morning PEFR but not on evening PEFR. It is not clear why morning PEFR is more responsive to PM than evening PEFR. A possible reason is that airway narrowing in people suffering from asthma is frequently at its worst in the early morning hours. Morning PEFR is not influenced by daily activities or medication used later during the day, and it may therefore be a more sensitive indicator of airway narrowing than evening PEFR (Pride, 1992; Timonen and Pekkanen, 1997).

With respect to the interpretation of our results, several limitations should be considered. Although our models accounted for autocorrelation of the events and for the effect of temperature and relative humidity, unmeasured air pollutants could also have been responsible for the lowering of lung function in the study rather than PM alone. It should be noted that, while some studies showed 
independent effects of the gaseous pollutants, in a number of studies where PM was highly correlated with other gaseous pollutants the PM effect estimates remained robust after adjustment for gaseous pollutants (Delfino et al., 1998; Jalaludin et al., 2000; Tolbert et al., 2000; Yu et al., 2000). In addition, as concentrations of gaseous pollutants $\left(\mathrm{O}_{3}, \mathrm{NO}_{2}, \mathrm{SO}_{2}\right.$, and $\left.\mathrm{CO}\right)$ in the community concerned were low during the sampling period, confounding of the PM associations by other air pollutants is less likely in our study (Taiwan EPA, 2003-2005).

The current study is also limited in the scope of inferences that can be made as particle exposures were represented only by total mass concentrations. Further advancement in assessing personal exposure is needed, which includes assessment of allergenic sources that may influence airway inflammation or induce bronchoconstriction. These exposure assessment methodologies should be developed for use in future epidemiologic research (Delfino et al., 2004).

Finally, our panel of asthmatic children had physiciandiagnosed asthma. Although the mixed-effect models we applied in the analysis have the advantage of adjustment for individual differences by random-effect models, it is possible that a more accurate classification of individuals based on objective indices of asthma, such as bronchial hyperactivity, would strengthen the associations. It has been shown that individuals with greater airway liability, for example, are more acutely responsive to air pollution, regardless of asthma diagnosis (Boezen et al., 1998; McConnell et al., 1999).

\section{Conclusion}

The current study presented several trends between personal PM exposures and asthmatic children's PEFR measurements, of which some are not necessarily statistically significant. In brief, notable findings tend to implicate that not only fine particles $\left(\mathrm{PM}_{2.5}\right)$ but also coarse particles $\left(\mathrm{PM}_{2.5-10}\right)$ are likely to contribute to exacerbation of asthmatic conditions. Stronger lagged effect (lag 2) and cumulative effect (2-day mean) of PM on the decrements in morning PEFR were found in the study. Finally, personal PM exposures were more suitable for evaluating the association between particle pollution and the PEFR changes than ambient PM monitoring data.

\section{Acknowledgments}

The authors thank all of the subjects who participated in this study. Fixed-site monitoring data were provided by Taiwan EPA. This study was funded by the Environmental Protection Bureau of Taipei County.

\section{References}

Akaike H. A new look at the statistical model identification. IEEE Trans Automat Contr 1974;19:716-23.

Barnes PJ, Jonsson B, Klim JB. The costs of asthma. Eur Respir J 1996;9:636-42.

Boezen M, Schouten J, Rijcken B, Vonk J, Gerritsen J, Zee S van der, et al. Peak expiratory flow variability, bronchial responsiveness and susceptibility to ambient air pollution in adults. Am J Respir Crit Care Med 1998;158:1848-54.

Bourotte C, Curi-Amarante AP, Forti MC, Pereira LAA, Braga AL, Lotufo PA. Association between ionic composition of fine and coarse aerosol soluble fraction and peak expiratory flow of asthmatic patients in Sao Paulo city (Brazil). Atmos Environ 2007;41:2036-48.

Brunekreef B, Holgate ST. Air pollution and health. Lancet 2002;360 (9341):1233-42.

Brunekreef B, Forsberg B. Epidemiological evidence of effects of coarse airborne particles on health. Eur Respir J 2005;26:309-18.

Chan CC, Wu TH. Effects of ambient ozone exposure on mail carriers' peak expiratory flow rates. Environ Health Perspect 2005;113 (6):735-8

Chang LT, Koutrakis P, Catalano PJ, Suh HH. Assessing the importance of different exposure metrics and time-activity data to predict 24-h personal $\mathrm{PM}_{2.5}$ exposures. J Toxicol Environ Health-Part A 2003;66(16-19):1825-46.

Chang LT, Lin YJ, Tang CS. The prevalence of asthma for children of elementary school in eight towns of Taipei County. Fu Jen J Med 2006;4(2):61-72.

Chuang KJ, Chan CC, Chen NT, Su TC, Lin LY. Effects of particle size fractions on reducing heart rate variability in cardiac and hypertensive patients. Environ Health Perspect 2005;113:1693-7.

Delfino RJ, Murphy-Moulton AM, Becklake MR. Emergency room visits for respiratory illnesses among the elderly in Montreal: association with low level ozone exposure. Environ Res 1998;76:67-77.

Delfino RJ, Quintana PJE, Floro J, Gastañaga VM, Samimi BS, Kleinman MT, et al. Association of FEV1 in asthmatic children with personal and microenvironmental exposure to airborne particulate matter. Environ Health Perspect 2004;112(8):932-41.

Diggle PJ, Heagerty P, Liang KY, Zeger SL. Analysis of longitudinal data. New York: Oxford University Press; 2002.

Dockery DW, Pope III CA, Xu X, Spengler JD, Ware JH, Fay ME, et al. An association between air pollution and mortality in six US cities. N Engl J Med 1993;329:1753-9.

Espinosa AJF, Rodriguez MT, De la Rosa FJB, Sanchez JCJ. Size distribution of metals in urban aerosols in Seville (Spain). Atmos Environ 2001;35:2595-601.

Ferrence R, Ashley MJ. Protecting children from passive smoking. $\mathrm{Br}$ Med J 2000;321:310-31.

Gielen MH, Van Der Zee SC, Van Wijnen JH, Van Steen CJ, BrunekreefB. Acute effects of summer air pollution on respiratory health of asthmatic children. Am J Respir Crit Care Med 1997;155: 2105-8.

Howard-Reed C, Rea AW, Zufall MJ, Burke JM, Williams RW, Suggs $\mathrm{JC}$, et al. Use of a continuous nephelometer to measure personal exposure to particles during the U.S. Environmental Protection Agency Baltimore and Fresno panel studies. J Air Waste Manage Assoc 2000;50:1125-32.

Hsieh KH, Shen JJ. Prevalence of childhood asthma in Taipei, Taiwan, and other Asian Pacific countries. J Asthma 1988;25:73-82.

Jalaludin BB, Chey T, O'Toole BI, Smith WT, Capon AG, Leeder SR. Acute effects of low levels of ambient ozone on peak expiratory flow rate in a cohort of Australian children. Int J Epidemiol 2000;29: 549-57. 
Jan IS, Chou WH, Wang JD, Kuo SH. Prevalence and major risk factors for adult bronchial asthma in Taipei City. J Formos Med Assoc 2004;103:259-63.

Kuo LC, Shau WY, Yang PC, Kuo SH. Trends in asthma mortality in Taiwan, 1981-2000. J Formos Med Assoc 2003;102:534-8.

Lighty JS, Veranth JM, Sarofim AF. Combustion aerosols: factors governing their size and composition and implications to human health. J Air Waste Manage Assoc 2000;50(9):1565-618.

Lipfert FW, Wyzga RE. Statistical considerations in determining the health significance of constituents of airborne particulate matter. J Air Waste Manag Assoc 1999;49(9):182-91.

Mar TF, Norris GA, Larson TV, Wilson WE, Koenig JQ. Air pollution and cardiovascular mortality in Phoenix, 1995-1997. Revised analyses of time-series studies of air pollution and health. special report. Boston, MA: Health Effects Institute; 2003. p. 177-82.

McConnell R, Berhane K, Gilliland F, London SJ, Vora H, Avol E, et al. Air pollution and bronchitic symptoms in Southern California Children with asthma. Environ Health Perspect 1999;107:757-60.

Neas LM, Dockery DW, Koutrakis P, Tollerud DJ, Speizer FE. The association of ambient air pollution with twice daily peak expiratory flow rate measurements in children. Am J Epidemiol 1995;141:111-22.

Pekkanen J, Timonen KL, Ruuskanen J, Reponen A, Mirme A. Effects of ultrafine and fine particles in urban air on peak expiratory flow among children with asthmatic symptoms. Environ Res 1997;74: 24-33.

Penttinen P, Timonen KL, Tiittanen P, Mirme A, Ruuskanen J, Pekkanen J. Number concentration and size of particles in urban air: effects on spirometric lung function in adult asthmatic subjects. Environ Health Perspect 2001;109:319-23.

Peters A, Dockery DW, Heinrich J, Wichmann HE. Short-term effects of particulate air pollution on respiratory morbidity in asthmatic children. Eur Respir J 1997a;10:872-9.

Peters A, Wichmann HE, Tuch T, Heinrich J, Heyder J. Respiratory effects are associated with the number of ultrafine particles. Am J Respir Crit Care Med 1997b;155:1376-83.

Peters A, Dockery DW, Muller JE, Mittleman MA. Increased particulate air pollution and the triggering of myocardial infarction. Circulation 2001;103:2810-5.

Pope III CA, Thun MJ, Namboodiri MM, Dockery DW, Evans JS, Speizer FE, et al. Particulate air pollution as a predictor of mortality in a prospective study of US adults. Am J Respir Crit Care Med 1995;151:669-74.

Pride NB. Physiology. In: Clark THJ, Godlfrey S, Lee HT, editors. Asthma. 3rd ed. London: Chapman and Hall Medical; 1992. p. 14-72.

Romieu I, Meneses F, Ruiz S, Sienra JJ, Huerta J, White MC, et al. Effects of air pollution on the respiratory health of asthmatic children living in Mexico City. Am J Respir Crit Care Med 1996;154:300-7.

Romieu I, Meneses F, Ruiz S, Huerta J, Sienra JJ, White M, et al. Effects of intermittent ozone exposure on peak expiratory flow and respiratory symptoms among asthmatic children in Mexico City. Arch Environ Health 1997;52:368-76.

Schwartz J. Airborne particles and daily deaths in 10 US cities. Revised analyses of time-series studies of air pollution and health. Special report. Boston, MA: Health Effects Institute; 2003. p. 211-8.

Schwartz J, Neas LM. Fine particles are more strongly associated than coarse particles with acute respiratory health effects in schoolchildren. Epidemiology 2000;11:6-10.

Segala C, Fauroux B, Just J, Pascual L, Grimfeld A, Neukirch F. Shortterm effect of winter air pollution on respiratory health of asthmatic children in Paris. Eur Respir J 1998;11:677-85.

Sheppard L, Levy D, Norris G, Larson TV, Koenig JQ. Effects of ambient air pollution on nonelderly asthma hospital admissions in Seattle, Washington, 1987-1994. Epidemiology 1999;10:23-30.

Timonen KL, Pekkanen J. Air pollution and respiratory health among children with asthmatic or cough symptoms. Am J Respir Crit Care Med 1997; 156:546-52.

Tolbert PE, Mulholland JA, Maclntosh DL, Xu F, Daniels D, Devine $\mathrm{OJ}$, et al. Air quality and pediatric emergency room visits for asthma in Atlanta, Georgia. Am J Epidemiol 2000;151:798-810.

Trenga CA, Sullivan JH, Schildcrout JS, Shepherd KP, Shapiro GG, Liu LJS, et al. Effect of particulate air pollution on lung function in adult and pediatric subjects in a Seattle panel study. Chest 2006;129: $1614-22$.

US EPA. National Ambient Air Quality Standards for particulate matter. Final rule. Fed Reg 2006;71:61144-233.

Vedal S, Petkau J, White R, Blair J. Acute effects of ambient inhalable particles in asthmatic and nonasthmatic children. Am J Respir Crit Care Med 1998;157:1034-43.

Von Klot S, Wolke G, Tuch T, Heinrich J, Dockery DW, Schwartz J, et al. Increased asthma medication use in association with ambient fine and ultrafine particles. Eur Respir J 2002;20:691-702.

WHO. Air quality guidelines global update 2005. Copenhagen: World Health Organization, Regional Office for Europe; 2005.

Yearbook of Environmental Protection Statistics, Republic of China, 2003-2005. Taipei: Environmental Protection Administration, Executive Yuan; 2003-2005.

Yu O, Sheppard L, Lumley T, Koenig JQ, Shapiro GG. Effects of ambient air pollution on symptoms of asthma in Seattle-area children enrolled in the CAMP study. Environ Health Perspect 2000;108:1209-14. 